\title{
Cone Beam Computed Tomography a Noval Innovation for assessing the Canal Morphology of Maxillary First Bicuspid
}

\author{
${ }^{1} \mathrm{M}$ Remya, ${ }^{2}$ VP Prabath Singh
}

\begin{abstract}
Aim: To evaluate the root canal morphology of maxillary first premolar using Cone beam computed tomography (CBCT).

Materials and methods: A total of 125 teeth were selected and CBCT scans were taken and following factors were recorded number of roots, number of root canals, anatomy, and configuration of canals.
\end{abstract}

Results: Overall $88 \%$ teeth had two roots. Most frequent canal configuration was type I in $93.6 \% ; 94.4 \%$ teeth had single canal exiting in single apical foramen.

Conclusion: Within the limitation of the study, it was concluded that among the study population, there is a high incidence of two-rooted maxillary first bicuspid with two canals with type I Vertucci canal configuration.

Keywords: Cone beam computed tomography, Maxillary first premolar, Root canal morphology.

How to cite this article: Remya M, Singh VPP. Cone Beam Computed Tomography a Noval Innovation for assessing the Canal Morphology of Maxillary First Bicuspid. Cons Dent Endod J 2017;2(1):4-7.

Source of support: Nil

Conflict of interest: None

\section{INTRODUCTION}

"Off all the phases of anatomic study of human system one of the most complex is the pulp space anatomy" Barret MT, Dental Cosmos

Root canal system is complex and varies with each individual teeth. A thorough knowledge of tooth anatomy, root canal morphology, careful interpretation of angled radiographs, adequate access and exploration are prerequisite for successful root canal therapy. ${ }^{1}$ In the case of a maxillary first premolar, the root morphology including

${ }^{1}$ Postgraduate Student, ${ }^{2}$ Professor and Head

1-2Department of Conservative Dentistry and Endodontics Amrita School of Dentistry, Kochi, Kerala, India

Corresponding Author: M Remya, Postgraduate Student Department of Conservative Dentistry and Endodontics Amrita School of Dentistry, Kochi, Kerala, India, Phone: +919567370349, e-mail: drremya88@gmail.com its canal anatomy can vary significantly in different individuals and populations.

The maxillary first premolar has two cusps, a buccal and a lingual, each being sharply defined. Most have two roots, and two root canals bifurcate it of half its length. When only one root is present, two root canals are usually found. ${ }^{2}$ Single root ranges from 22 to $66 \%$, with two roots from 33 to $84 \%$, and three with roots from 0 to $6 \%{ }^{3}$

However, there have been several reports of anomalous morphology of the roots and root canals, with distinct racial predilections. Walker ${ }^{4}$ found that Asians have different percentages of canal configurations than those reported in studies on Caucasians and Africans. ${ }^{5}$

The conventional technique for studying root canal morphology has been tooth clearing, dye injection, and decalcification methods while some researchers have employed radiography. Radiographic evaluation has been mostly restricted to periapical radiography in two planes or digital radiography. Superimposition of structures and image distortion are drawbacks to the use of this technique.

Recently, a noninvasive and extremely sensitive tool has been suggested for such studies, namely, Cone beam computed tomography (CBCT). Cone beam computed tomography imaging allows a three-dimensional evaluation of teeth and their adjacent structures. ${ }^{3}$ According to Kim et al, ${ }^{6}$ CBCT scan can enhance the understanding of root canal anatomy, with the potential of improving the outcome of endodontic treatment. ${ }^{7}$ Literature regarding root and canal morphology of teeth in the Kerala population is very sparse.

The present study was conceived to evaluate using CBCT anatomical variations of the root canals of the maxillary first premolar in Kerala population.

\section{MATERIALS AND METHODS}

The study was undertaken at Amrita School of Dentistry following institutional ethical committee approval.

A total of 125 extracted maxillary first premolars were selected using criteria as described by Wheeler. ${ }^{2}$ The teeth were collected from the Department of Oral and Maxillofacial Surgery, Amrita School of Dentistry, extracted due to trauma, periodontal, and orthodontic 


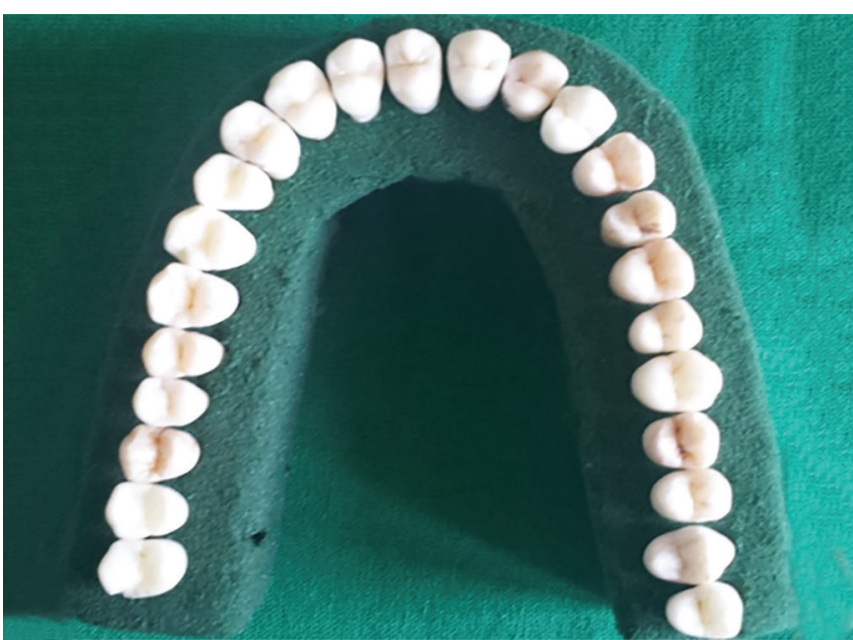

Fig. 1: Samples for CBCT number of roots

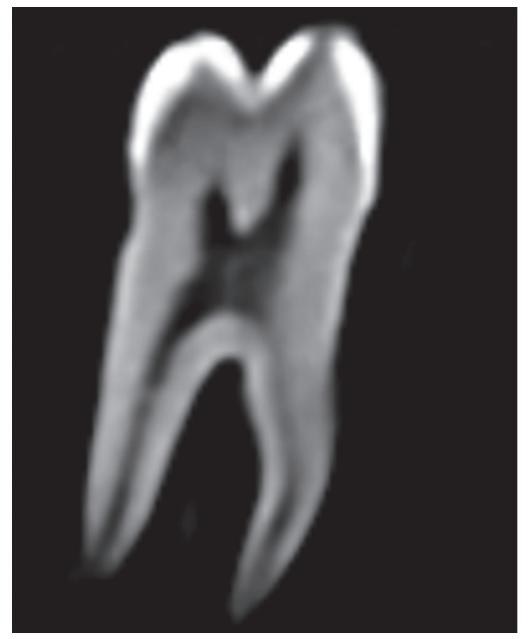

Fig. 3: Separate root

reasons. The specimens were cleaned and stored in saline until use.

For CBCT evaluation, specimens were arranged in a template (Fig. 1). Cone beam computed tomography scans of the teeth were taken using Kodak Carestream CS 9300 machine, and the scans were assessed by a single investigator using CS three-dimensional imaging software.

The following were recorded:

- Number of roots

- Number of root canals

- Anatomy and configuration of canals

In this study, canal morphology was determined based on Vertucci's classification. ${ }^{7}$ The data were entered on an Excel spreadsheet and descriptive analysis was done.

\section{RESULTS}

Of the 125 first premolar teeth studied, $88 \%$ had two roots and $12 \%$ had single root (Fig. 2). Of the $88 \%$ two-rooted premolars, $74 \%$ had two separate roots (Fig. 3) while $27 \%$ had fused roots (Fig. 4).

\section{Number of roots}

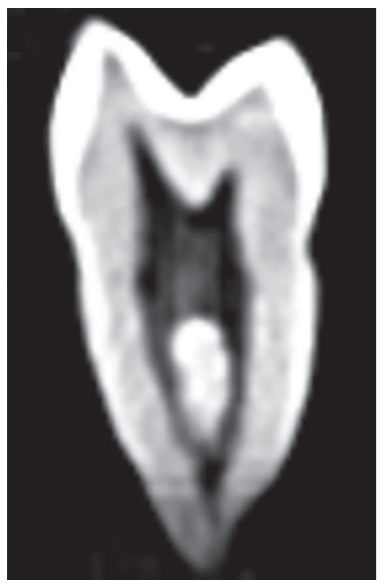

Fig. 2: Single root

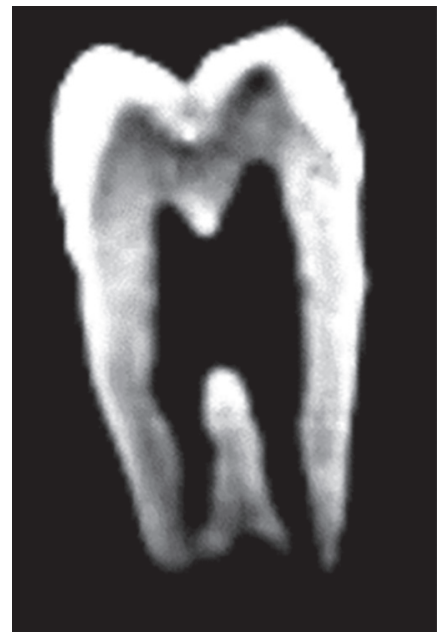

Fig. 4: Fused roots

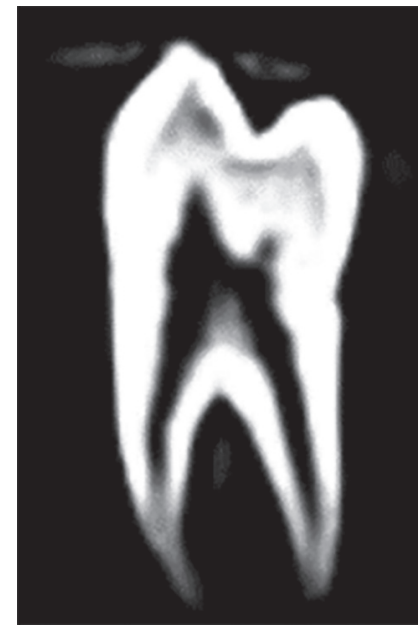

Fig. 5: Type I

When the internal root anatomy was examined, Vertucci type I canal configuration was seen in $93.6 \%$ (Fig. 5), with a single root canal extending from the pulp chamber and exiting in a single apical foramen. Type II configuration was seen in $3.1 \%$ (Fig. 6) and type VI in 


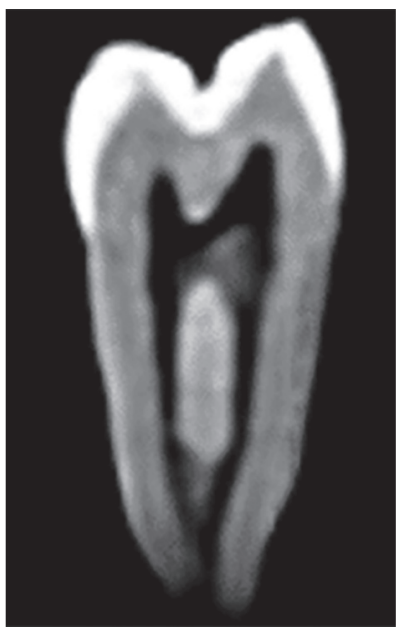

Fig. 6: Type II

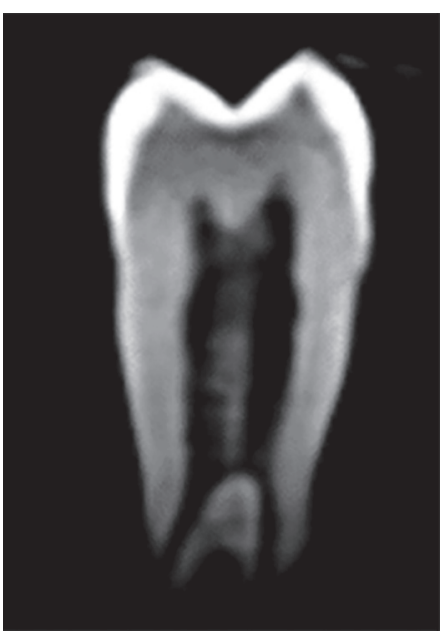

Fig. 7: Type VI
Table 1: Percentage of number of roots and canal configuration

\begin{tabular}{llll}
\hline No of roots & Two rooted (88\%) & Single rooted \\
\hline & Fused & Separated & $12 \%$ \\
& $27 \%$ & $74 \%$ & \\
\hline Canal configuration & Type I & Type II & Type VI \\
\hline & $93.6 \%$ & $3.1 \%$ & $2.3 \%$ \\
\hline
\end{tabular}

$2.3 \%$ (Fig. 7). The variations were usually seen in the single-rooted teeth.

Single canal existing in single apical foramen was found in $94.4 \%$ teeth, while only $4 \%$ teeth showed two canals joining and exiting at single apical foramen and $3 \%$ showed two canal joining and exiting in two foramina (Table 1).

\section{DISCUSSION}

Understanding of pulp space anatomy of teeth is a prerequisite to the delivery of high-quality root canal treatment. An inadequate understanding of the three-dimensional nature of pulp space may lead to failures. ${ }^{8}$

Cone beam computed tomography or digital volume tomography produces three-dimensional scans of the maxillofacial skeleton using an extraoral imaging scanner at a lower radiation dose than conventional CT. Cone beam computed tomography was used to study root canal morphology in the present study as it is a noninvasive method to evaluate the anatomy in axial, sagittal, and coronal sections and provide a three-dimensional image of root canal system. ${ }^{9}$ It has been shown to be more accurate than digital radiographs in determining root canal systems and can also evaluate the canal configuration in vivo, thereby useful in clinical assessment. Neelakantan et $\mathrm{al}^{10}$ reported that $\mathrm{CBCT}$ can detect the root canal system as accurately as canal staining and clearing techniques. ${ }^{11}$

Maxillary premolars have a complex and highly variable anatomy. ${ }^{1}$ The variation in number of roots and canal configuration makes endodontic treatment on these teeth complex. ${ }^{10}$ Different studies have reported variations in canal configurations in maxillary first premolars. ${ }^{10}$

Vertucci in 1984 studied the canal configuration of human permanent teeth and reported that maxillary first premolar was the only tooth which had all the eight types of canal configurations. Pineda and Kuttler (1972) reported that in maxillary premolars, $50.1 \%$ had one canal and $49.4 \%$ had two canals at the apex. This finding was not in agreement with the study by Green (1973) where one canal in $8 \%$ and two canals at apex in $92 \%$ cases were reported. ${ }^{9}$

The incidence of a single-rooted maxillary first premolar was reported as 22.0 to $55.8 \%$ by Pecora et al. ${ }^{10}$ Loh reported $50.6 \%$ incidence of single-rooted teeth in a Singaporean population, while Carns and Skidmore reported the highest incidence of $72 \% .{ }^{5,10,11}$ All these reports concur that ethnicity plays a significant role in the canal morphology. The differences in the results of these morphology studies may be due to variations of examination methods, classification systems, sample sizes, and ethnic background of tooth sources.

In the present study, the canal configurations were visualized in three dimensions using CBCT. It can, therefore, be used as an adjunct to existing diagnostic aid. Among the teeth examined, 93.6\% teeth had type I canal configuration. Type II configuration was seen in 3.1\% and type VI in $2.3 \%$. Type I canal configuration is easy to identify and treat. Teeth with a complex root canal system (types II, III, V, VI, VII, and VIII) are difficult to identify and treat with cleaning, shaping, and obturation. Clinically, it is important to know that the single root canal splits into multiple canals at certain point of root canal length and the level of separation most often go unnoticed and are difficult to manage. ${ }^{12}$

About $62.6 \%$ of maxillary first premolars were found to have two roots and $12 \%$ teeth had single root. All of 
the teeth had "two canals" irrespective of single/double root, ${ }^{1}$ which was consistent with the findings of the studies done by Kartal et al (Turkey), Lipski et al (Poland), and Atieh $^{13}$ (Saudi Arabia). ${ }^{8}$

The present assessment shows that root and canal morphology of maxillary first premolar is highly variable and changes with different ethnic groups.

\section{CONCLUSION}

Among the study population, maxillary first premolars showed a $62.6 \%$ incidence of two roots with two distinct canals, with $94.4 \%$ exiting in two apical foramen. Cone beam computed tomography analysis is a noninvasive and effective tool for assessing root and canal morphology, which is an adjunct to routine technique to improve outcome of endodontic treatment.

\section{REFERENCES}

1. Ingle, B. Endodontics. 6th ed. Mosby Inc.; 2002.

2. Nelson, SJ.; Ash, MM. Wheeler's dental anatomy, physiology, occlusion. 9th ed. Elsevier Inc.; 2010.

3. Abella F, Teixidó LM, Patel S, Sosa F, Duran-Sindreu F, Roig M. Cone beam computed tomography analysis of the root canal morphology of maxillary first and second premolars in a Spanish population. J Endod 2015 Aug;41(8):1241-1247.

4. Kenneth, Louis. Cohens pathway of pulp. 10th edition. Elsevier

5. Vertucci FJ. Root canal morphology and its relationship to endodontic procedures. Endod Top 2005 Mar;10(1):3-29.

6. Kim Y, Lee SJ, Woo J. Morphology of maxillary first and second molars analyzed by cone-beam computed tomography in a Korean population: variations in the number of roots and canals and the incidence of fusion. J Endod 2012 Aug;38(8): 1063-1068

7. Mirzaie M, Zaban PT, Mohammadi V. Cone beam computed tomography study of root canals in a Hamadani population in Iran. Avicenna J Dent Res 2015;7:25-31.

8. Özcan E, Çolak H, Hamidi MM. Root and canal morphology of maxillary first premolars in a Turkish population. J Dent Sci 2012 Dec;7(4):390-394.

9. Matherne RP, Angelopoulos C, Kulild JC, Tira D. Use of Cone beam computed tomography to identify root canal systems in vitro. J Endod 2008 Jan;34(1):87-89.

10. Gupta S, Sinha DJ, Gowhar O, Tyagi SP, Singh NN, Gupta S. Root and canal morphology of maxillary first premolar teeth in north Indian population using clearing technique: an in vitro study. J Conserv Dent 2015 May-Jun;18(3):232-236.

11. Sharma D, Mathur M. A computed tomographic study of canal variations in maxillary and mandibular first premolar teeth in Jaipur population - an in vitro study. People J Sci Res 2011;4:1-5.

12. Atieh MA. Root and canal morphology of maxillary first premolars in a Saudi population. J Contemp Dent Pract 2008 Jan;9(1):46-53.

13. Neelakantan P, Subbarao C, Ahuja R, Subbarao CV, GutmannJL. Cone beam computed tomography study of root and canal morphology of maxillary first and second molars in an Indian population. J Endod 2010 Oct;36(10):1622-1627.

14. Martins JN, Marques D, Mata A, Caramês J. Root and root canal morphology of the permanent dentition in a Caucasian population: a Cone beam computed tomography study. Int Endod J 2016 Nov.

15. Lipski M, Łagocka R, Tomasik M. Root and canal morphology of the first human maxillary premolar. Durham Anthropol J 2003;12:2-3. 